\title{
PENGGUNAAN Trichoderma sp. SEBAGAI AGENSIA PENGENDALIAN TERHADAP Pyricularia oryzae Cav. PENYEBAB BLAS PADA PADI
}

\author{
Yulida Sarif Hidayat, Muhammad Nurdin \& Suskandini R.D \\ Jurusan Agroteknologi, Fakultas Pertanian Universitas Lampung \\ J1. Prof. Dr. Soemantri Brodjonegoro no. 1 Bandar Lampung 35145 \\ Email: hidayatsarief@gmail.com
}

\begin{abstract}
ABSTRAK
Salah satu kendala dalam budidaya tanaman padi adalah penyakit blas padi yang disebabkan oleh jamur Pyricularia oryzae Cav. Salah satu cara pengendalian yang dapat dilakukan adalah penggunaan agensia hayati ramah lingkungan. Penelitian ini bertujuan mengetahui keefektifan Trichoderma sp. untuk menghambat pertumbuhan Pyricularia oryzae Cav. in vitro. dan mengetahui keefektifan Trichoderma sp. untuk mengurangi keparahan penyakit blas pada tanaman padi di lapangan. Penelitian ini terdiri dari dua sub percobaan, pertama yaitu sub percobaan secara in vitro untuk menguji antagonisme Trichoderma sp. terhadap Pyricularia oryzae serta sub percobaan yang kedua yaitu menguji kefektifan Trichoderma sp. mengurangi keparahan penyakit blas pada tanaman padi di lapangan. Pada sub percobaan kedua disusun dalam rancangan acak lengkap dengan dua perlakuan dan 10 ulangan. Perlakuan terdiri atas perlakuan benih disertai dengan penyemprotan suspensi konidia Trichoderma sp. terhadap padi kultivar Ciherang (T1) dan kontrol tanpa pemberian Trichoderma sp. (T0). Data keparahan penyakit yang diperoleh dianalisis dengan sidik ragam (Anova), dan dilanjutkan dengan uji BNT (Beda Nyata Terkecil) pada taraf nyata 5\% atau $1 \%$. Hasil penelitian menunjukkan bahwa Trichoderma sp. mampu menghambat pertumbuhan Pyricularia oryzae secara in vitro dan perlakuan perendaman benih serta penyemprotan menggunakan suspensi konidia Trichoderma sp. mengurangi keparahan penyakit blas pada tanaman padi.
\end{abstract}

Kata Kunci : Padi, Pyricularia oryzae Cav, Trichoderma sp.

\section{PENDAHULUAN}

Padi (Oryza sativa L.) sebagai tanaman pangan terpenting di Indonesia memiliki beberapa faktor pembatas dalam pertumbuhannya. Salah satu faktor pembatas dalam produksi padi adalah penyakit blas yang disebabkan oleh jamur Pyricularia oryzae. P.oryzae selain menyerang daun, juga menyerang malai (bulir), dan leher (neck). Penyakit blas telah menurunkan hasil panen padi di Asia tenggara dan Amerika selatan sekitar 30-50\%, dan mengakibat kan kerugian jutaan dolar Amerika. Di Indonesia serangan penyakit blas dapat mencapai luas 1.285 juta ha atau sekitar $12 \%$ dari total luas areal pertanaman padi di Indonesia (Shimamoto et al., 2001 dalam Sijabat, 2007).

Penyakit blas dapat menular secara langsung dari tanaman sakit ke tanaman sehat di pertanaman. Selain itu, penyakit blas juga dapat tertular melalui benih, sehingga diperlukan perhatian terhadap kualitas benih padi yang akan ditanam. Sampai saat ini pengujian kesehatan benih padi belum pernah dilakukan secara benar sehingga benih sehat hanya dicerminkan oleh keseragaman benih dengan tingkat kemurnian varietas yang tinggi, dan daya tumbuh minimal $80 \%$ (Anonim, 2007a). Sampai saat ini pengendalian jamur P.oryzae masih menggunakan fungisida sintetik, sehingga jika penggunaan fungisida dilakukan terus menerus dapat mencemari lingkungan. Oleh karena itu perlu diteliti caracara atau metode pengendalian yang ramah lingkungan dengan menggunakan mikroorganisme.

Salah satu mikroorganisme yang dapat digunakan untuk menekan penyakit tanaman adalah jamur Trichoderma sp. Jamur Trichoderma sp. diketahui efektif dalam menekan beberapa patogen tanaman seperti Armillaria mellea, Pythium sp., Phytophthora sp., Rhizoctonia solani, Sclerotium rolfsii, dan Heterobasidium annosum (Parker et al., 1985 dalam Murniasih, 2009). Oleh karena itu pada penelitian ini akan dicoba pengaruh Trichoderma sp. terhadap Pyricularia oryzae pada padi yang bertujuan mengetahui keefektifan Trichoderma sp. untuk menghambat pertumbuhan Pyricularia oryzae Cav. in vitro dan keefektifan Trichoderma sp. untuk mengurangi keparahan penyakit blas pada tanaman padi. 


\section{BAHAN DAN METODE}

Penelitian ini dilakukan di Laboratorium Penyakit Tumbuhan Jurusan Agroteknologi Fakultas Pertanian Universitas Lampung, dari bulan Mei sampai dengan Desember 2013. Alat yang digunakan ialah cawan petri, gelas piala, gelas ukur, otoklaf, meja laminar air flow, timbangan elektrik, nampan plastik, jarum ose, bor gabus, polibag, bunsen, aluminium foil, plastik tahan panas. Bahan yang digunakan ialah alkohol $70 \%$, aquades, media PSA, benih padi varietas Ciherang. Untuk perlakuan benih dan penyemprotan digunakan agensia hayati berupa Trichoderma sp. koleksi Klinik Proteksi Tanaman, Fakultas Pertanian Universitas Lampung.

Penelitian ini dilaksanakan dengan metode rancangan acak lengkap (RAL). Percobaan terdiri atas dua perlakuan yaitu perlakuan benih disertai dengan penyemprotan menggunakan suspensi konidia Trichoderma sp. terhadap padi kultivar Ciherang dan kontrol tanpa pemberian Trichoderma sp. Masingmasing perlakuan diulang $10 \mathrm{kali}$.

Perlakuan yang diaplikasikan pada padi adalah : (1). Perendaman biji padi Ciherang dalam air biasa dan tidak ada penyemprotan apapun sebagai kontrol (T0) dan (2). Perendaman biji padi Ciherang dalam suspensi konidia Trichoderma sp. yang dilanjutkan dengan penyemprotan suspensi konidia Trichoderma sp. pada tanaman padi umur 40 hari setelah tanam (T1). Peubah yang diamati adalah keparahan penyakit. Setelah data keparahan penyakit didapatkan, data dianalisis secara statistik dengan menggunakan sidik ragam (Anova), dan dilanjutkan dengan uji BNT (Beda Nyata Terkecil) pada taraf nyata $5 \%$ atau $1 \%$.

Penyiapan biakan Pyricularia oryzae Cav. Pyricularia oryzae diisolasi dari daun padi Ciherang yang menunjukkan gejala terserang blas daun dari pertanaman padi di Kecamatan Gadingrejo Kabupaten Pringsewu. Gejala daun padi yang terserang blas yaitu adanya bercak belah ketupat berwarna abu-abu kecoklatan.

Daun padi yang menunjukkan gejala bercak belah ketupat dicuci dengan air bersih, direndam dalam larutan $\mathrm{NaOCl}$ 0,5\% selama 30 detik, kemudian dibilas dengan air steril. Benih tersebut diisolasi menggunakan media PSA (Potato Succrose Agar) yang ditambah dengan asam laktat. Pertumbuhan jamur hasil isolasi yang diharapkan berupa Pyricularia oryzae diamati selama 7 hingga 10 hari inkubasi pada suhu $30^{\circ} \mathrm{C}$. Isolat dimurnikan dan diperbanyak dengan media PSA

Penyiapan biakan Trichoderma sp. Jamur antagonis yang digunakan pada penelitian ini merupakan isolat jamur Trichoderma sp. koleksi Klinik Proteksi
Tanaman Fakultas Pertanian Universitas Lampung. Isolat murni Trichoderma sp. diidentifikasi dan diperbanyak pada media PSA. Pada setiap cawan petri diletakkan 1 potongan induk Trichoderma sp. berukuran bor gabus yang berdiameter $1 \mathrm{~cm}$, dan diinkubasikan selama 7 hingga 10 hari

Uji penghambatan Trichoderma sp. terhadap Pyricularia oryzae secara in vitro. Uji antagonis dilakukan dengan cara menumbuhkan dua jamur yaitu Trichoderma sp. dan Pyricularia oryzae dalam satu cawan petri secara berlawanan. Cawan petri yang telah berisi media PSA padat dibalik dan pada bagian belakangnya dibuat garis yang saling berpotongan pada tengah cawan petri menggunakan spidol permanen. Kemudian pada garis tersebut ditentukan dua titik yang berjarak $3 \mathrm{~cm}$ dari tepi cawan secara berlawanan. Titiktitik tersebut digunakan sebagai tempat infestasi jamur Trichoderma sp. dan Pyricularia oryzae yang masingmasing berumur 3 hari dan 5 hari inkubasi. Masingmasing diinfestasikan pada titik yang telah ditentukan, kemudian diinkubasikan di ruang dengan suhu $30^{\circ} \mathrm{C}$ (gambar 1).

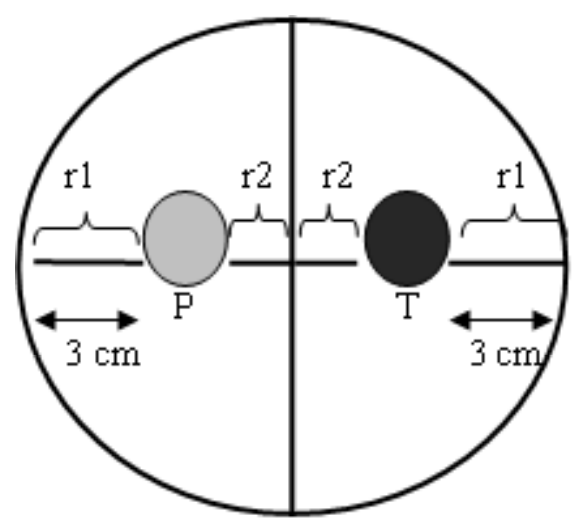

Gambar 1. Rancangan aplikasi tempat infestasi jamur Trichoderma sp. dan Pyricularia oryzae pada cawan petri. $\mathrm{P}=$ Biakan Pyricularia oryzae, $\mathrm{T}=$ Biakan Trichoderma sp. $\mathrm{r} 1$ = Jari-jari koloni Pyricularia oryzae yang menjauhi Trichoderma sp., $\mathrm{r} 2$ = Jari-jari koloni Pyricularia oryzae yang mendekati Trichoderma sp.

Pengamatan dilakukan setiap hari dengan mengukur jari-jari koloni Pyricularia oryzae yang berlawanan arah dan menuju ke arah jamur Trichoderma sp. Kemudian persentase penghambatan diukur dengan menggunakan rumus (Mahadtanapuk dkk., 2007 dalam Kurniawati, 2012): Suspensi 


$$
P R=\frac{r 1-r 2}{r 1} \times 100 \%
$$

Keterangan:

$\mathrm{PR}=$ Persentase penghambatan pertumbuhan jamur r1 = Jari-jari koloni Pyricularia oryzae yang menjauhi Trichoderma sp.

r2 = Jari-jari koloni Pyricularia oryzae yang mendekati Trichoderma sp.

Trichoderma sp. dibuat dengan cara mensuspensikan konidia dan konidiofor Trichoderma sp. yang tumbuh pada media PSA (Potato Succrose Agar) berumur 3 hari inkubasi, ke dalam air steril sebanyak $10 \mathrm{ml}$ kemudian dikocok sampai homogen. Kerapatan konidia dihitung dengan menggunakan alat haemocytometer sehingga mendapatkan kerapatan 38,5 x 10² butir konidia/ ml. Suspensi $P$. oryzae dibuat dengan cara mensusp.ensikan konidia dan konidiofor $P$. oryzae dari media PSA (Potato Succrose Agar) berumur 5 hari inkubasi ke dalam air steril sebanyak $10 \mathrm{ml}$ kemudian dikocok sampai homogen. Kerapatan konidia dihitung dengan menggunakan alat haemocytometer sehingga mendapatkan kerapatan 38,5 x $10^{2}$ butir konidia $/ \mathrm{ml}$. Tahapan Pengujian pada perlakuan dengan Trichoderma sp. disajikan pada gambar 2, sedangkan perlakuan tanpa Trichoderma sp. (kontrol) disajikan pada gambar 3.

Pengamatan. Peubah yang diamati dalam penelitian ini ialah keparahan penyakit. Pengamatan keparahan penyakit blas dilakukan terhadap tanaman padi dari saat benih mulai tumbuh hingga menunjukkan gejala bercak daun berbentuk belah ketupat.

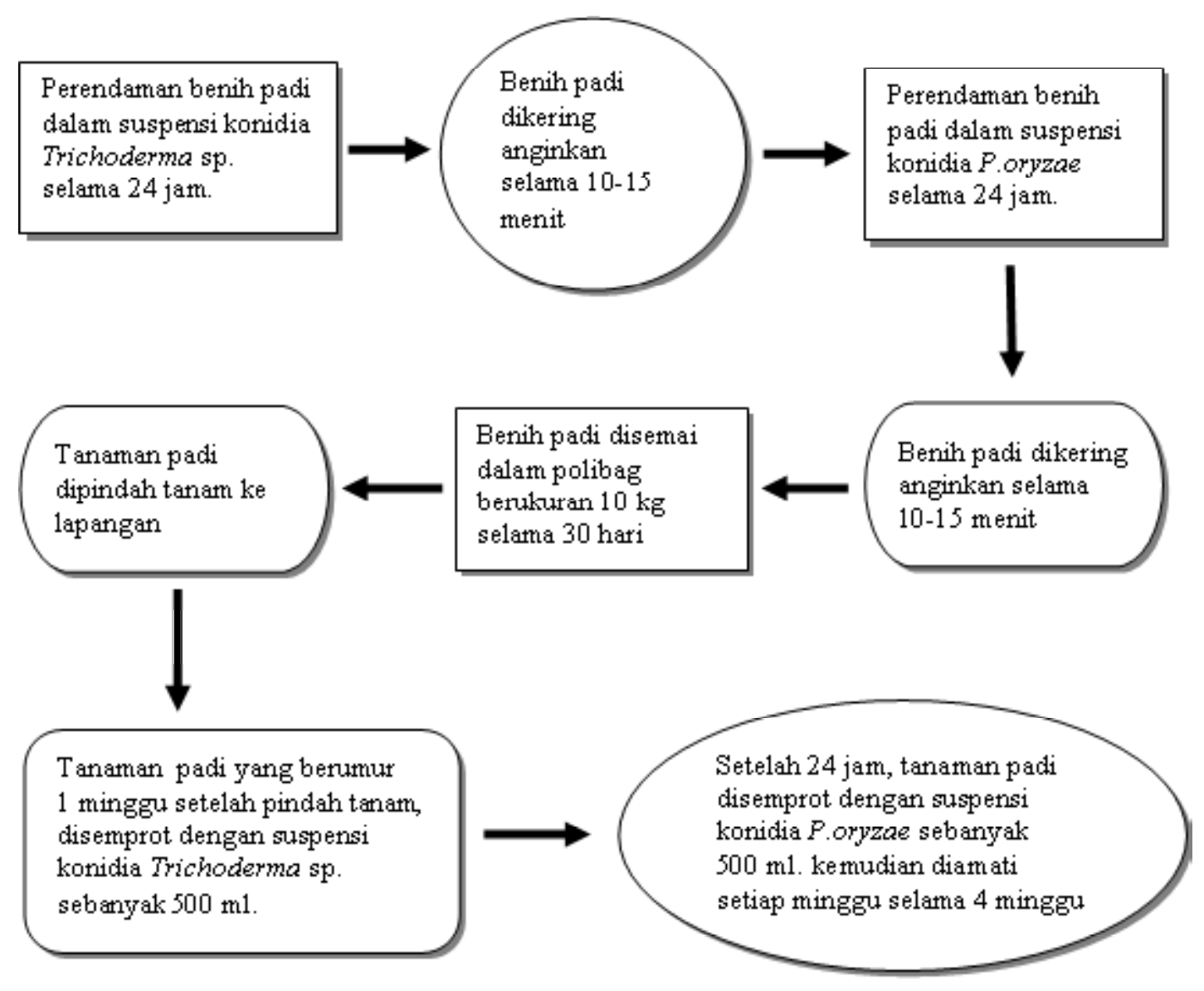

Gambar 2. Perlakuan dengan Trichoderma sp. 


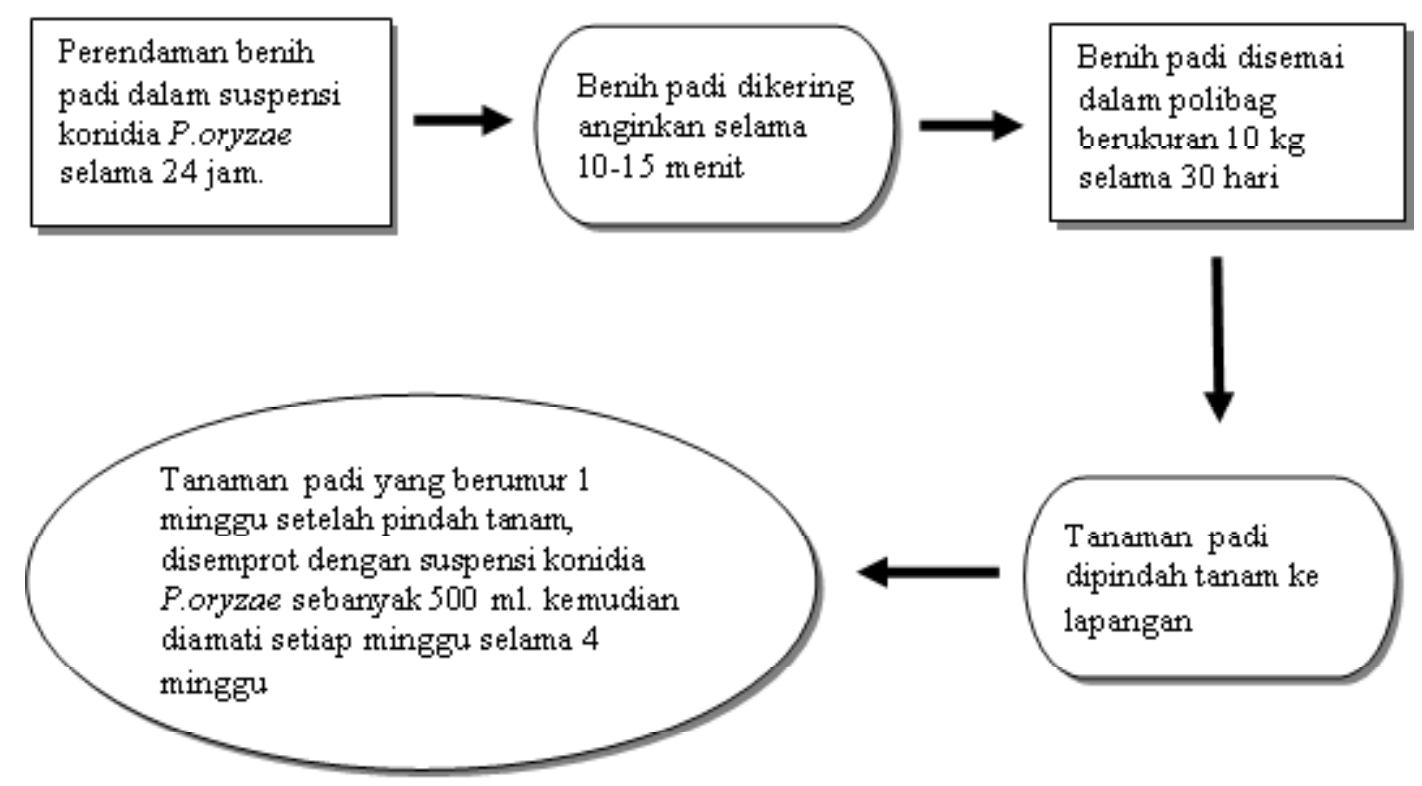

Gambar 3. Perlakuan tanpa Trichoderma sp. (kontrol).

Keparahan penyakit dihitung dengan menggunakan rumus sebagai berikut (Dirjen Pertanian Tanaman Pangan, 2003) :

$$
I=\frac{\sum(n i \times v i)}{N \times V} \times 100 \%
$$

Keterangan :

I = Intensitas Serangan

ni = Jumlah Tanaman atau Bagian Tanaman Contoh dengan Skala Kerusakan vi

vi = Nilai Skala Kerusakan Contoh ke-i

$\mathrm{N}=$ Jumlah Tanaman atau Bagian Tanaman Contoh yang Diamati

$\mathrm{V}=$ Nilai Skala Kerusakan Tertinggi

Nilai skala kerusakan yang digunakan adalah sebagai berikut :

$0=$ Daun sehat

$1=1-20 \%$ permukaan daun terinfeksi

$2=21-40 \%$ permukaan daun terinfeksi

$3=41-60 \%$ permukaan daun terinfeksi

$4=61-80 \%$ permukaan daun terinfeksi

$5=81-100 \%$ permukaan daun terinfeksi

\section{HASIL DAN PEMBAHASAN}

Hasil isolasi jamur Pyricularia oryzae. Isolat Pyricularia oryzae yang digunakan diperoleh dari hasil isolasi daun padi yang menunjukkan gejala terserang blas dengan gejala bercak berbentuk belah ketupat. Dari pengamatan secara mikroskopis diperoleh konidia yang bersekat-sekat, jarang bercabang, tunggal, berbentuk bulattelur dengan ujung runcing, jika masak bersekat 2 , dengan ukuran 0-22 x 10-12 $\mu \mathrm{m}$ (Gambar 4). Hal ini sesuai dengan identifikasi menurut Barnett (1960).

Persentase Rerata Penghambatan Trichoderma sp. Terhadap Pertumbuhan Pyricularia oryzae. Hasil penelitian menunjukkan bahwa Trichoderma sp. mempengaruhi pertumbuhan Pyricularia oryzae pada media tumbuh PSA. Pengaruh Trichoderma sp. berupa penghambatan Pyricularia oryzae tampak pada hari ke-2 inkubasi. Pada hari ke-2 inkubasi, persentase penghambatan $11,2 \%$, dan meluas pada hari ke-3 menjadi $14,26 \%$, berlanjut pada hari ke-4 sebesar $17,83 \%$, dan pada hari ke-5 inkubasi Trichoderma sp. telah tumbuh hingga ke pinggir cawan petri. Rerata persentase pengaruh penghambatan Trichoderma sp. terhadap pertumbuhan Pyricularia oryzae dapat dilihat pada Gambar 5.

Penghambatan pertumbuhan Pyricularia oryzae oleh Trichoderma sp. diduga karena terjadi persaingan atau kompetisi. Dalam hal ini kebutuhan akan zat makanan yang sama dapat menyebabkan terjadinya persaingan antara kedua jamur tersebut. Jamur yang dapat menyesuaikan diri paling cepat maka akan mengalami pertumbuhan lebih subur. Jika dua jamur ditumbuhkan di dalam suatu media yang sama, maka jamur yang unggul dapat bertahan, sedangkan jamur yang lemah dapat punah (Dwidjoseputro, 1985). 


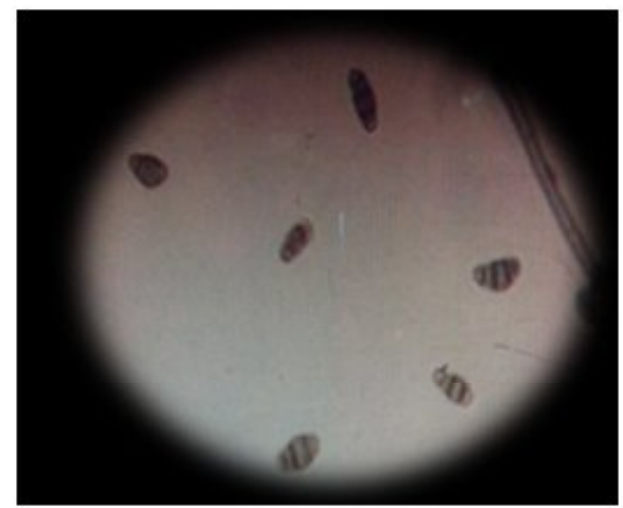

Gambar 4. Konidia Pyricularia oryzae (perbesaran 10x40)

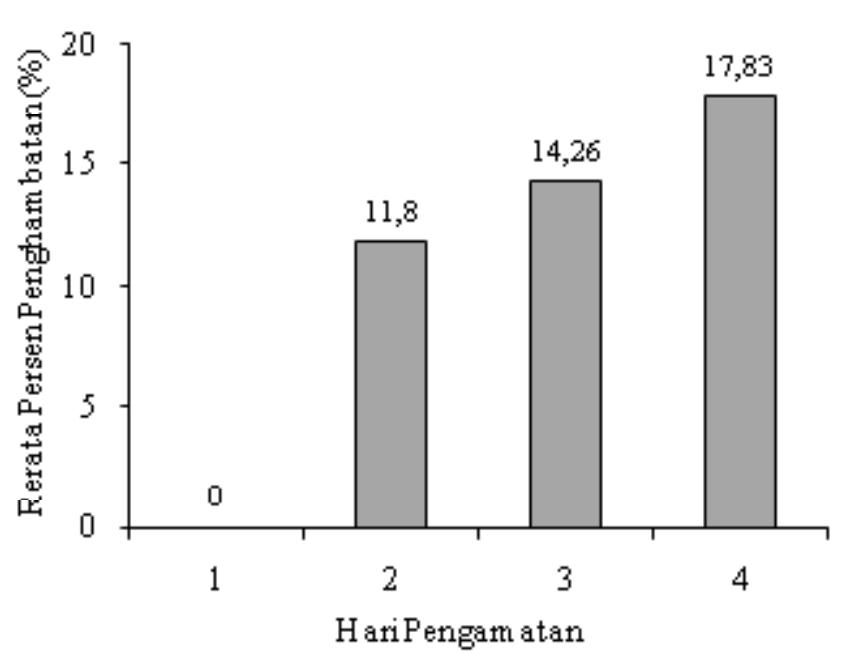

Gambar 5. Grafik rerata persentase pengaruh penghambatan Trichoderma sp. Terhadap pertumbuhan Pyricularia oryzae (\%).

Keparahan Penyakit Blas Pada Tanaman Padi. Hasil analisis sidik ragam pengamatan keparahan penyakit blas menunjukkan bahwa perendaman benih dan penyemprotan tanaman padi menggunakan agensia hayati Trichoderma sp. mampu mengurangi keparahan penyakit blas. Hasil pengamatan terhadap keparahan penyakit pada $7,8,9$, dan 10 minggu setelah pindah tanam (MSPT) disajikan dalam Gambar 6.

Hasil penelitian menunjukkan bahwa perlakuan perendaman benih dan penyemprotan menggunakan jamur Trichoderma sp. menyebabkan perbedaan keparahan penyakit blas pada padi dibandingkan dengan tanpa aplikasi Trichoderma sp. Perendaman biji padi dan penyemprotan dengan Trichoderma sp. mampu mengurangi keparahan penyakit blas pada 8, 9 dan 10

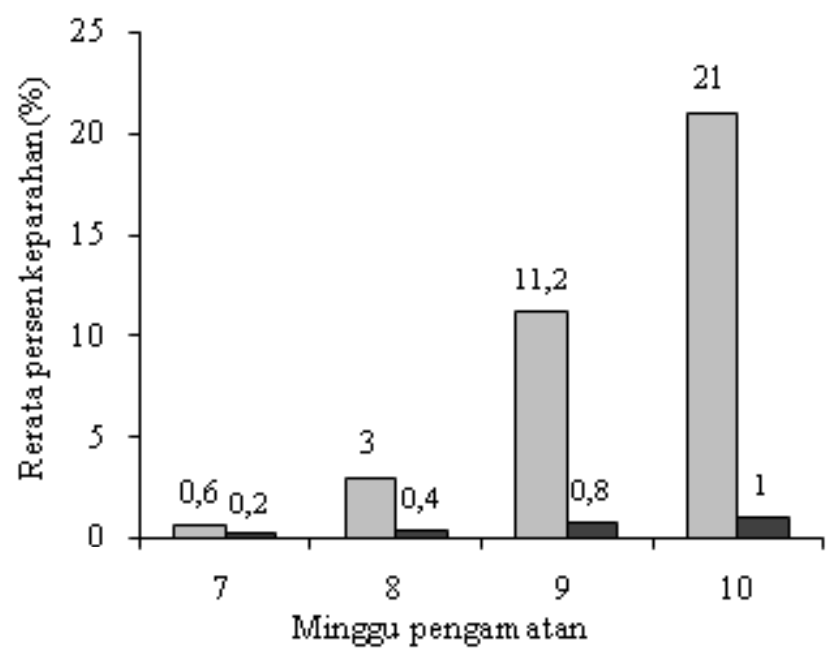

Gambar 6. Grafik rerata persentase keparahan penyakit blas (P.oryzae) pada tanaman padi (\%). = tanpa Trichoderma sp. (T0), $\square=$ dengan Trichoderma sp. (T1).

MSPT. Suspensi konidia Trichoderma sp. yang digunakan untuk melindungi benih ternyata menyebabkan penghambatan keparahan penyakit blas dari 8 MSPT sampai 10 MSPT. Hal ini sesuai dengan Tandiabang dan Pakki (2007), bahwa Pyricularia oryzae menginfeksi berat pada padi berumur dua bulan atau delapan minggu setelah tanam. Pada umur tersebut padi mulai berbunga sehingga fisiologinya menjadi rentan.

Mekanisme penghambatan Pyricularia oryzae oleh Trichoderma sp. di duga disebabkan oleh kompetisi antara kedua jamur yang telah ditunjukkan pada uji kompetisi pertumbuhan jamur secara in vitro. Trichoderma sp. yang diaplikasikan terlebih dahulu akan lebih cepat berkembang di permukaan tanaman padi 
karena ada penambahan air gula pada suspensi Trichoderma sp. sebagai sumber nutrisi. Selanjutnya diduga Trichoderma sp. menggunakan kemampuannya yang lain untuk menghambat keparahan penyakit blas daun dengan cara Trichoderma sp. mengekskresikan enzim b-(1,3)- glukanase dan kitinase yang diduga dapat menghancurkan dinding sel jamur. Kemampuan Trichoderma sp. mengekskresikan enzim b-(1,3)glukanase dan kitinase yang menghancurkan dinding sel jamur dinyatakan oleh Chet (1987). Selain itu menurut Papavizas (1985) Trichoderma sp. dapat menghasilkan antibiotik yaitu trichodermin dan viridin.

\section{KESIMPULAN}

Berdasarkan hasil penelitian dapat disimpulkan bahwa Trichoderma sp. menghambat pertumbuhan Pyricularia oryzae secara in vitro. Perlakuan perendaman benih dan penyemprotan menggunakan suspensi konidia Trichoderma sp. mengurangi keparahan penyakit blas pada padi.

\section{DAFTAR PUSTAKA}

Anonim.2007 a. Interaksi Poligenik Ketahanan Padi Terhadap Blas. http://biogen.litbang.deptan. go.id. Diakses pada tanggal : 12 januari 2014.

Barnett, H.L, 1960. Imperfect Fungi. Burgess Publishing Company. Virginia. $225 \mathrm{hlm}$.

Chet, I. 1987. Innovative Approaches to Plant Diseases Control. Jhon Wiley and Sons, A WileyInterscience Publication, USA. pp. 11-210.

Direktorat Jenderal Pertanian Tanaman Pangan. 2003. Pedoman Pengujian Pestisida Berbahan Aktif
Majemuk. Direktorat Jenderal Bina Sarana Pertanian. Jakarta.76 p.

Dwidjoseputro, D. 1985. Dasar-Dasar Mikrobiologi. Djambatan. Malang. $207 \mathrm{hlm}$.

Kurniawati, Y. 2012. Pengaruh Trichoderma viridae dan Pseudomonas fluorescens Terhadap Pertumbuhan Phytophthora palmivora Butl. Pada Berbagai Media Tumbuh. Skripsi. Universitas Lampung. Bandar Lampung. $60 \mathrm{hlm}$

Murniasih, Y. 2009. Pengaruh Aplikasi Tepung Kencur dan Kunyit Terhadap Kemampuan Antagonis Trichoderma viridae Pers. Pada Phytophthora palmivora L. Penyebab Busuk Buah Kakao Secara In Vitro. Skripsi. Universitas Lampung. Bandar Lampung. $35 \mathrm{hlm}$

Papavizas, G. C. 1985. Trichoderma \& Gliocladium : Biology, Ecology, and Potential For Biocontrol. Annual Reviews of Phytopathol. Maryland. 23: 23-54 pp.

Semangun, H. 1991. Penyakit-Penyakit Tanaman Pangan di Indonesia. Gadjah Mada University Press. Yogyakarta. $449 \mathrm{hlm}$.

Sijabat, O.N.S.BR. 2007. Epidemi Penyakit Blas (Pyricularia oryzae Cav.) Pada Beberapa Varietas Padi Sawah (Oryza sativa L) Dengan Jarak Tanam Berbeda Dilapangan. Skripsi. Universitas Sumatera Utara. Medan. 103 Hlm.

Tandiabang, J. dan S. Pakki. 2007. Penyakit Blas (Pyricularia grisea) dan Strategi Pengendalian nya pada Tanaman Padi. Prosiding Seminar Ilmiah dan Pertemuan Tahunan PEI dan PFI XVIII. Komda Sul-Sel. Hal : 241-245. 